\title{
NOTAS
}

\section{Sacrificios humanos en santuarios de altura en la región de Arequipa}

\author{
Humans sacrifices in highland shrines of the Arequipa región
}

\author{
Marco Antonio Morales Galarza \\ https://orcid.org/0000-0003-4854-3031 \\ Universidad Nacional Mayor de San Marcos \\ marco.morales9@unmsm.edu.pe
}

\section{INTRODUCCIÓN}

Según Pearson (2008), el sacrificio humano puede ser considerado como el último intercambio recíproco o como la sumisión de los vivos a lo sobrenatural, que se expresa mediante el regalo o tributo que se les entrega a los dioses, que consiste en entregar lo más preciado para el ser humano, que sería la vida humana. Sin embargo, como señala Pearson (2008) el concepto de sacrificio humano es difícil de definir o identificar, precisamente porque puede haber una delgada línea que lo separa o distingue de la ejecución o exterminio de rivales o prisioneros de guerra o del autosacrificio altruista. Como indica Pearson, generalmente el sacrificio humano está dirigido a entidades sobrenaturales y es llevado a cabo bajo los auspicios de especialistas en rituales. Lo señalado por Pearson se ve plasmado en los sacrificios realizados por los incas en los santuarios de altura, en volcanes de la región de Arequipa como el Misti, Picchu Picchu, Chachani, Ampato, Sara Sara.

Pearson (2008) señala la existencia de dos tipos de sacrificios, los de gran escala, es decir, aquellos que son característicos o frecuentes en el caso de los funerales de 
los gobernantes autocráticos de los estados emergentes, como el caso de las tumbas egipcias de la primera dinastía de Abidos en el 3100-2890 a. C. .Por ejemplo, para el caso andino tenemos el descubrimiento de la tumba del Señor de Sipán del siglo III d.c, vinculado a la cultura Moche, en el cual podemos ver al personaje principal asociado a otros individuos, quienes habrían sido sus sirvientes y que fueron enterrados juntos al señor de Sipán para que le siguiera sirviendo en la "otra vida".

Respecto al otro tipo de sacrificios que menciona Pearson (2008), es el sacrificio ofrecido a las entidades o deidades sobrenaturales, los cuales reciben ofrendas humanas. Estas deidades suelen ser elementos de la naturaleza, como montañas, volcanes, lagos, lagunas, entre otros. Por ejemplo, para el área andina tenemos los sacrificios realizados en los santuarios de altura por parte de los incas, durante la ceremonia de la Capacocha. Tenemos el caso del volcán de Llullaillaco, Cerro el Toro, Cerro el Plomo, entre otros.

\section{Caso de estudio}

Para el caso de estudio veremos el tema de los sacrificios humanos realizados en los santuarios de altura, en el sur del Perú, en la región de Arequipa, estas investigaciones fueron llevadas a cabo y conducidas por Johan Reinhard y arqueólogos de la Universidad Católica Santa María de Arequipa. En las cuales participaron los arqueólogos José Chávez (2001) y María Ceruti (2013) quienes publicaron artículos sobre el tema, de los cuales nos basamos para el presente trabajo. A continuación, se procederá a presentar una descripción de los sacrificios humanos hallados en los santuarios de altura en la cima de las montañas de la región de Arequipa.

\section{Volcán Misti}

Respecto al santuario de altura ubicado en el volcán Misti, las investigaciones de Reinhard y Chávez permitieron confirmar la existencia del santuario del volcán Misti en el borde del cráter. Como señala María Ceruti (2013) Los incas tomaron la decisión de construir el santuario de altura del volcán Misti, en un sector del labio interior del cráter. En base al emplazamiento del sitio se plantea que los rituales que se realizaron en el sitio habrían estado relacionados con el apaciguamiento del volcán. El hecho que sustenta y apoya esta hipótesis es la orientación de la arquitectura del complejo principal, el cual no coincide con los otros casos, es decir, con otros santuarios de altura, sino que se adapta a los contornos del borde del cráter.

Respecto a los sacrificios humanos hallados en el santuario del volcán Misti. Los entierros fueron hallados en estructuras circulares, una a la derecha y otra a la izquierda, las cuales estaban conformados por tres entierros superpuestos. El primer individuo apareció asociado a ofrendas y los dos siguientes a mayor profundidad fueron hallados con abundante ajuar funerario. Este patrón de entierros superpues- 
tos se halló en las dos estructuras circulares. Haciendo una totalidad de seis víctimas sacrificadas en el volcán Misti.

\section{Pichu Picchu}

El Pichu Picchu es un macizo de múltiples cumbres o "muchos picos". Entre ellos, destaca la cumbre Coronado con una altitud de 5630 de altitud, esta destaca entre todas las cimas del Pichu Picchu por haber sido elegida por los incas para la construcción de un santuario de altura, en el cual se realizaron sacrificios humanos y se depositaron ofrendas (Ceruti, 2013).

Respecto a los sacrificios hallados en las cimas del Pichu Picchu, las investigaciones realizadas por Ceruti y Chávez en el año 1996, revelaron la presencia de dos víctimas humanas enterradas dentro de la plataforma del santuario de altura. Estos sacrificios se trataban de dos subadultos, un niño y una niña que tenía el cráneo deformado intencionalmente.

\section{Ampato}

Como señala Chávez (2001) en la cumbre principal del cráter de Ampato a 6830 metros de altitud. Los incas construyeron una plataforma, en dicho lugar se llevaban a cabo las ofrendas al Apu Ampato, estas ofrendas estarían a cargo de un sumo sacerdote. Lo cual coincide con lo planteado por Pearson (2008) cuando señala que estas ofrendas eran llevadas a cabo por especialistas en rituales.

Respecto a la ofrenda ofrecida al Apu Ampato, esta consistió en el sacrificio de la conocida Juanita, una niña de entre 12 y 14 años de edad, que es descrita por Chávez (2001) como una mensajera real y divina. Se pudo determinar que Juanita falleció de un certero golpe de macana que le produjo un traumatismo encéfalo craneal que la llevó a la muerte. Junto a Juanita, como acompañantes, en la montaña del Ampato a 5800 metros de altitud, fueron sacrificados un niño y dos niñas de 8 y 12 años de edad, asociados a una serie de ofrendas muy valoradas por los incas. Por ejemplo, Spondylus, estatuillas de oro y plata, finos textiles, etc. (Chávez, 2001).

\section{CONCLUSIONES}

Como pudimos ver en el caso de los sacrificios humanos realizados como parte de ofrenda a las deidades, ha sido una práctica realizada por la sociedad Inka, como también por sociedades preincaicas. Como señala Pearson (2008) estos tipos de sacrificios (múltiples y dedicados a deidades sobrenaturales) fueron realizados por diversas culturas en todo el mundo.

Como señala Ceruti (2013) efectivamente, los volcanes sagrados de la región de Arequipa fueron utilizados por los incas como escenarios de ofrendas y sacrificios, 
lo cual se ve expresado en el hallazgo de santuarios en las cimas de los volcanes. La importancia que tuvieron estos volcanes para el estado incaico, se ve representado en la cantidad de víctimas humanas y ofrendas recuperadas durante las investigaciones arqueológicas realizadas en los santuarios de altura, como es el Misti, Pichu Picchu, Ampato, Sara Sara.

Como menciona Ceruti (2013) la ceremonia incaica destinada a atenuar la ira de los dioses, era llevada a cabo en caso de terremotos, inundaciones, grandes sequías o alguna otra amenaza. Lo cual se puede ver en este caso, debido a que en base a las investigaciones realizadas en el volcán Misti, se determinó que este entró en erupción durante los años 1440 y 1450, de esta manera estos sacrificios realizados estarían vinculados a apaciguar la ira de los dioses como señalan Chávez (2001) y Ceruti (2013). Esta información también se ve contrastada con los datos etnohistóricos.

Cabe resaltar que el tema de los sacrificios humanos realizados por los incas en lugares de gran altura, no solo se dieron en los andes centrales, sino que los incas también construyeron santuarios de altura, en otras regiones, en lo que es actualmente Argentina y Chile. Por ejemplo, tenemos el caso del sacrificio en el volcán Llullaillaco, presentado por Martínez (2005) y otros casos como: Cerro El Plomo, Cerro El Toro, Aconcagua, presentados en el artículo de Quevedo et al. (2002). Este tipo de sacrificios suelen hallarse en extraordinarias condiciones de preservación debido a las bajas temperaturas a las que se encuentran. Además, estos sacrificios suelen hallarse asociados a ofrendas muy variadas y altamente valoradas por los incas.

Es difícil hallar algo similar en tiempos preincaicos, debido a que las culturas pre incas, como argumenta Ceruti (2013) se conformaban con adorar a los volcanes más elevados desde una prudente distancia, debido a la dificultad para escalarla, pero seguramente lo que influyó en mayor medida fue el temor y respeto que sentían por estas deidades. Sin embargo, para la sociedad inca esta práctica se vuelve común y la podemos ver en una serie de casos, en diversas regiones. Lo cual también se relaciona con las prácticas realizadas por los incas, que consistían en edificar santuarios o centros ceremoniales en lugares muy valorados por los pueblos conquistados, con la finalidad de hacer más efectiva la conquista de estos pueblos, pues no solo era una conquista política y económica, sino que también ideológica. Tal como indica Ceruti (2013) los incas al ubicar sitios rituales sobre las cimas de las montañas, lograban un mayor control político, económico y religioso sobre las poblaciones conquistadas. Esta práctica realizada por los incas de conquista ideológica, se ve en muchas regiones, por ejemplo, lo menciona Astuhuamán (2018) para la región de Piura, y también Perales (2008) para la región de Junín.

Por último, las investigaciones realizadas en los santuarios de altura al sur del Perú, en la región de Arequipa, coinciden con los relatos de los cronistas que se- 
ñalan que normalmente las ofrendas humanas solían ser sub adultos, pues en la mayoría de los casos se halló el cuerpo sacrificado de niños y niñas, como es el caso de Juanita, quien tenía entre 12 y 14 años de edad. De igual manera coincide con los datos presentados por los cronistas sobre el tema de la Capacocha, que consiste en la ceremonia mediante la cual se sacrificaban a niños como ofrendas a las deidades.

De igual manera, estas prácticas realizadas por los incas, como también por otras sociedades de distintas partes del mundo, demuestran ese rasgo que comparten en común, que trata sobre la creencia en la vida después de la muerte, lo cual se ve expresado en el esmero por conservar el cuerpo de los individuos o también por las ofrendas asociadas a los cadáveres, como vasijas, alimentos o herramientas que usaron en vida o el caso de los entierros múltiples, como el caso del señor de Sipán que fue enterrado junto a sus súbditos.

\section{REFERENCIAS BIBLIOGRÁFICAS}

Astuhuamán, C. (2018). Una aproximación a la cultura material de los Guayacundos durante el Intermedio Tardío. Revista de Etnohistoria, 1, 1-21.

Ceruti, M. (2013). Chachani, Misti y Pichu Picchu: Pasado y Presente de los Volcanes Sagrados de Arequipa. Anuario de Arqueología , 359-372.

Chávez, J. (2001). Investigaciones Arqueológicas de Alta Montaña en el Sur del Perú. Chungará. 33 (2). http://dx.doi.org/10.4067/S0717-73562001000200014

Martínez Armijo, I. (2005). Textiles inca en el contexto de la capacocha función y significado. Cusco: UNSAAC.

Parker, P. (2008). The Archaeology of Death and Burial. United States: Texas A\&M University Press.

Perales, M. (2004). El control Inka de las fronteras étnicas: reflexiones del valle de Ricrán en la sierra central del Perú. En: Chungara, Revista Antropológica Chilena, 36(2), 515-523

Quevedo y Durán. (1992). Ofrendas a los dioses en las montañas: Santuarios de Altura en la Cultura Inka. Boletín Museo Nacional de Historia Natural, 193-206. 


\section{SOBRE EL AUTOR}

\section{Marco Antonio Morales Galarza}

Estudiante de último ciclo de la carrera de arqueología de la Universidad Nacional Mayor de San Marcos, interesado en realizar investigaciones sobre arqueología del paisaje y patrones de asentamiento de las sociedades prehispánicas tardías. Actualmente viene desarrollando investigaciones arqueológicas en la sub cuenca del río Lampián, cuenca alta del río Chancay-Huaral. 